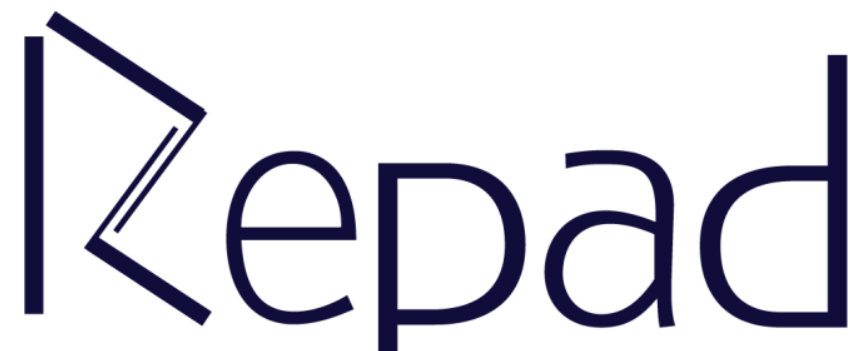

Vol. 2, n. 3, Dezembro/2018

Revista Estudos e

Pesquisas em Administração

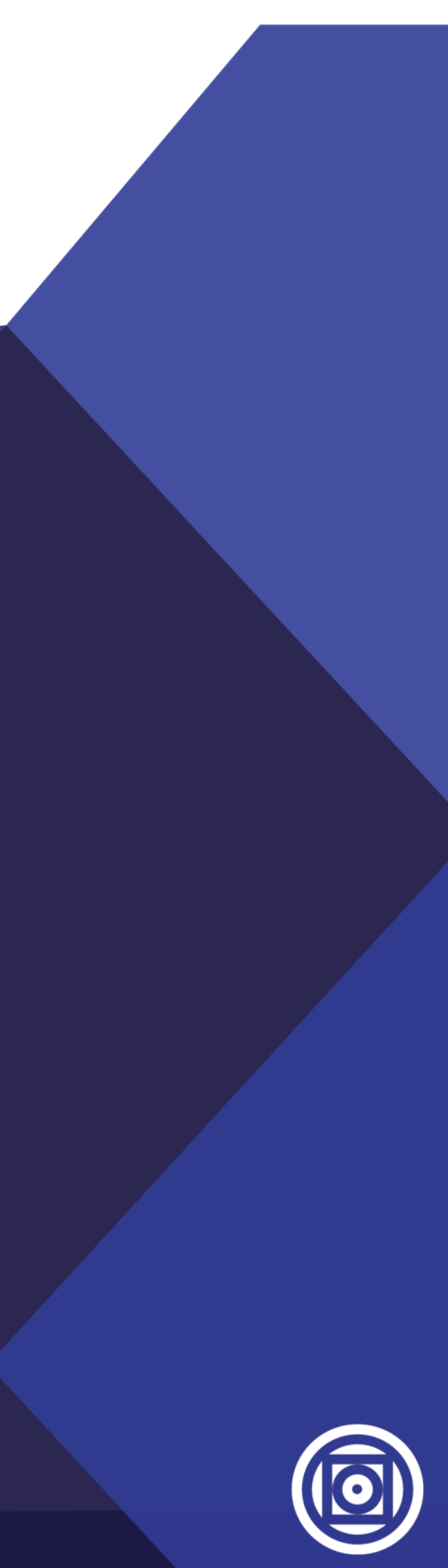




\title{
O CONTROLE SOCIAL NO CONSELHO ESTADUAL DE SAÚDE DE PERNAMBUCO EM 2017 E A BUROCRACIA WEBERIANA
}

\author{
Laís Carla Venâncio Rodrigues \\ Universidade Federal de Pernambuco \\ https://orcid.org/0000-0002-4562-3020
}

\begin{abstract}
RESUMO
O controle social é dado como a participação cidadã na gestão e fiscalização das ações da Administração Pública, possuindo garantia legal no Brasil. Os Conselhos de Saúde possuem caráter permanente e deliberativo, compostos por representantes do governo, prestadores de serviço, profissionais da área e usuários, atuando na formulação de estratégias e no controle da execução política na instância correspondente. O Estado Racional é sinônimo de Moderno, uma correspondência de superioridade de homens sobre outros, apoiada por meio da coação legítima. Uma burocracia com um funcionamento totalmente eficiente é um tipo ideal, uma estrutura ótima que deve ser almejada no âmbito estatal, sendo sua legitimação tida como dominação racional-legal. O objetivo desse trabalho é averiguar o nível de controle social praticado pelo Conselho Estadual de Saúde de Pernambuco em 2017 e relacioná-lo à teoria weberiana da burocracia. O procedimento metodológico foi composto por revisão bibliográfica e pesquisa documental através da análise das deliberações oficiais homologadas por resoluções e resumos de atas de reunião, uma vez que as primeiras são precursoras da materialização das atribuições regimentais na prática e as segundas são fontes de informação a respeito dos temas debatidos.
\end{abstract}

Palavras-chave: Controle social. Burocracia. Conselho de Saúde. Racionalidade. Democracia.

\section{THE SOCIAL CONTROL IN THE PERNAMBUCO STATE HEALTH COUNCIL IN 2017 AND WEBER'S BUREAUCRACY}

\begin{abstract}
Social control is defined as the citizen participation in the management and supervision of the actions of the Public Administration, with legal guarantee in Brazil. The Health Councils are permanent and deliberative, composed of representatives of government, service providers, professionals and users, acting in the formulation of strategies and in controlling the execution of policies in the corresponding instance. The Rational State is synonymous with the Modern, a connection of superiority of men over others, supported by legitimate coercion. A fully efficient bureaucracy is an ideal type, an optimal structure that must be sought at the state level, its legitimation being taken as rational-legal domination. The objective of this research is to verify the level of social control practiced by the State Health Council of Pernambuco in 2017 and relate it to Weber's bureaucracy theory. The methodological procedure was composed of bibliographical review and documentary research through the analysis of official deliberations approved by resolutions and summaries of minutes, because the former are precursors to the implementation of the regimental attributions in real life and the latter are sources of information about the issues discussed.
\end{abstract}

Keywords: Social control. Bureaucracy. Health Council. Rationality. Democracy. 


\section{INTRODUÇÃO}

No Brasil, o direito à participação popular no controle das ações do Estado está garantido na Constituição de 1988 e regulamentado em leis específicas, como por exemplo, a Lei Orgânica da Saúde (LOS), o Estatuto da Criança e do Adolescente (ECA), a Lei Orgânica da Assistência Social (LOAS) e o Estatuto das Cidades, as quais possuem instâncias de consulta e deliberações cidadãs, especialmente, por meio de Conselhos (LOPES, 2000).

O controle social pode ser classificado como uma forma de compartilhar o poder de decisão entre sociedade e Estado, um instrumento de expressão da democracia e da cidadania. Em outras palavras, é a capacidade que o ambiente possui de intervir nas políticas públicas por meio de uma interação mútua entre a coletividade e a instituição estatal. Essa prática pode ser realizada tanto no momento da definição das estratégias quanto no ato de fiscalizar, acompanhar e avaliar as condições de gestão, execução das ações e aplicação dos recursos financeiros destinados à efetivação de uma política pública (GONÇALVES et al., 2013).

O Conselho de Saúde é o órgão colegiado, de caráter permanente e deliberativo, integrante da estrutura básica das Secretarias de Saúde estatais, com competências fixadas em lei para desenvolver o controle social na área de sua atuação. Está presente nas três esferas por meio do Conselho Nacional de Saúde no âmbito federal, dos Conselhos Estaduais de Saúde nos estados, no Distrito Federal e nas cidades pelos Conselhos Municipais de Saúde. Porém, não estão limitados a estas instâncias, podendo haver Conselhos Locais de Saúde responsáveis por distritos sanitários. Seu formato administrativo possui características burocráticas, com regimento indicando suas metas e competências, assim como atividades pré-estabelecidas legalmente e impessoalidade na eleição dos conselheiros (BRASIL, 2013).

O sociólogo alemão Max Weber (1982) foi quem conferiu à burocracia a característica de pertencer a sistemas sociais relativamente avançados, principalmente, quanto ao capitalismo, em meados no século XX, tendo sua fonte de legitimidade no poder racional-legal. A burocracia é considerada um tipo ideal, um complexo racional-legal tipificado pelo formalismo, hierarquia, sistema de normas e prevalência da impessoalidade, por meio de métodos para a realização contínua dessas tarefas e para a execução dos direitos correspondentes.

Considerando que a razão de haver Conselhos de Saúde legitimamente estabelecidos no Brasil é garantir o controle social, por meio de segmentos populares, pergunta-se: o Conselho Estadual de Saúde de Pernambuco (CES/PE) está efetivamente deliberando a fim de proporcionar a execução de suas atribuições legais ou suas decisões se limitam a temas do seu funcionamento institucional interno, típico de um sistema burocrático inviabilizado?

Assim, o objetivo da presente pesquisa é verificar o nível de controle social exercido pelo Conselho Estadual de Saúde de Pernambuco (CES/PE) no ano de 2017, partindo das deliberações oficiais da instituição, uma vez que a efetiva ação ocorre após homologação da decisão institucional, e relacionar essa conjuntura à teoria weberiana da burocracia.

A estrutura metodológica do estudo é composta por revisão bibliográfica e pesquisa documental utilizando publicações oficiais do Conselho Estadual de Saúde de Pernambuco em sua página na internet, especificamente, resoluções e resumos de atas de reunião emitidos em 2017. Os primeiros documentos foram selecionados para análise a fim de conhecer as decisões que oficializam a efetiva execução das competências presentes no Regimento Interno do CES/PE, uma vez que a execução do controle social é regimentalmente precedida de uma deliberação formal, e os demais documentos informam a respeito dos temas abordados durante as reuniões do pleno no ano de 2017. 


\section{REFERENCIAL TEÓRICO}

\section{CONTROLE SOCIAL: CONCEITO GERAL}

No campo de estudo da Sociologia, o conceito de controle social passou a ser estruturado juntamente com o desenvolvimento dessa Ciência, sobretudo com as colaborações de Émile Durkheim (2007), que definiu a sociedade como um conjunto de fatos autônomos e harmonicamente interligados pela solidariedade, um mecanismo que vincula pessoas e fatos sociais e que em nada se assemelha à ideia de auxílio ao próximo.

Para o sociólogo francês, o controle social reforça o domínio da sociedade sobre os indivíduos, promovendo a integração dos fatos sociais ao todo e fazendo uso de métodos coercitivos se necessário. O Estado, a religião e o Direito são exemplos desse mecanismo que asseguram a solidariedade, porém, sua análise se detém principalmente entre os fenômenos "crime" e "pena", no qual o primeiro ameaça a ordem e o segundo é a reação coletiva que visa garantir a integração na entre os membros (DURKHEIM, 2007).

O sociólogo Karl Mannheim (1962) define o controle social como uma totalidade de ordenações da sociedade para influenciar o comportamento humano a fim de manter determinada ordem, sendo um meio de regular a conduta do indivíduo dentro de um padrão desejável por aqueles que governam e legislam o grupo controlado.

No campo da Gestão Pública, o controle social abrange a oportunidade de atuação dos grupos sociais por meio de uma via de participação democrática no controle das ações do Estado e dos gestores públicos, a fim de viabilizar a eficácia da atuação governamental, pleiteando transparência e publicidade dos atos administrativos (PEREIRA, 2003).

Conforme a Controladoria Geral da União (2012), o controle social pode ser conceituado como a participação cidadã na gestão, na fiscalização, no monitoramento e no controle das ações da Administração Pública, sendo um valioso mecanismo de prevenção da corrupção e de fortalecimento da cidadania. É um complemento fundamental à supervisão institucional realizado pelos órgãos responsáveis.

Outro termo pertinente na abordagem do controle social na gestão pública é o accountability, que de acordo com Fonseca et al. (2014) pode ser classificado como prática governamental fundamentada na responsabilização dos que exercem o poder, sendo possível a fiscalização e o controle pelos cidadãos, tanto individualmente como em grupos organizados. $\mathrm{O}$ accountability estende-se tanto aos poderes do Estado como aos dos advindos da sociedade e nesse âmbito, O’Donnell (1998) afirma a existência dos tipos vertical e horizontal. O primeiro é definido como o controle estatal pelos cidadãos, individualmente ou por ação coletiva, em relação àqueles que atuam em instituições estatais, eleitos ou não, sendo as eleições a principal forma dos entes sociais punirem ou premiarem o mandatário e seus aliados por meio do voto, em um meio com liberdade de opinião, de associação e de imprensa, com variadas fontes de informação e a possibilidade de articular reivindicações ou queixas contra agentes públicos sem risco de coerção.

O segundo se caracteriza pela existência de instituições estatais detentoras de poder e legalidade para realizar fiscalização, sanções ou impedimentos contra ações de outros agentes ou agências do Estado que se enquadrem em práticas delituosas ou onerosas, sendo uma relação entre iguais por meio do sistema de freios e contrapesos e da mútua vigilância entre os poderes, além de ser necessário o fortalecimento dos componentes liberais, republicanos e democráticos para garantir a robustez do mecanismo de controle (O`DONNELL, 1998).

Outro conceito de accountability chamado de societal ou social foi elaborado por Smulovitz e Peruzzotti (2000) e ampliou significativamente a conceituação vertical a partir do 
momento que incluiu nesta dimensão ações que vão além do processo sufragista, pois essa nova definição se classifica como uma forma de regulação não eleitoral, ainda de características de controle verticalizado, que se estabelece nas ações dos diversos grupos de associações de cidadãos, movimentos sociais e na mídia, com o objetivo de expor os defeitos e imperfeições dos governos, a fim de trazer novos quesitos para a agenda pública ou ativando a operação de agências fiscalizadoras horizontais, fazendo uso de ferramentas institucionais e não institucionais. Essa definição trata de trazer a sociedade civil organizada para o centro do debate a fim de que seja personagem operante no monitoramento das ações governamentais, estando inclusa ativamente no processo político.

Desde a Carta Magna de 1988, os Conselhos de Saúde têm assumido um importante papel para o aprimoramento do accountability societal a partir do momento em que se impõem como instâncias deliberativas das políticas públicas na área, assumindo a competência legal para exercer o controle público na aplicação de recursos, seja por meio do controle posterior, através de processos de avaliação baseados em resultados e na obediência aos procedimentos estabelecidos (FILGUEIRAS, 2011).

\section{CONTROLE SOCIAL NA SAÚDE NO BRASIL}

A atuação comunitária na saúde está na origem da reforma sanitária brasileira, no qual, na década de 1950, apresentou duas linhas principais de atuação: a natureza assistencial, a fim de atender aos mais pobres fora do campo produtivo ou sem empregabilidade, numa perspectiva de caridade, com base no trabalho voluntário e estruturado descontinuamente, e o modelo de seguro social, em que se beneficiavam aqueles inseridos na estrutura do mercado laboral, de acordo com as categorias profissionais, pois o acesso aos benefícios era diferenciado entre as diversas classes de trabalhadores (COSTA; VIEIRA, 2013).

Por volta da década de 1970, com o fim do milagre econômico e o agravamento das crises cíclicas do capitalismo, ressurgem com vigor alguns agrupamentos que pleiteavam demandas do povo, incluindo o direito de intervir nas políticas públicas por meio da criação de mecanismos de controle social. Esses movimentos sociais democráticos tinham como características autonomia, postura antiestatal e defesa da independência popular, uma vez que no período ditatorial o Estado era considerado um instrumento da classe dominante e suas instituições repressoras da nação, pois não havia interlocução com a comunidade organizada.

Com o processo de democratização brasileiro a partir dos anos de 1980, o debate sobre a participação dos cidadãos voltou à tona com uma dimensão de regulação de setores organizados da sociedade civil sobre o Estado (CORREIA, 2006).

No ano de 1986 aconteceu em Brasília a $8^{\text {a }}$ Conferência Nacional de Saúde, simultaneamente com a $1^{\text {a }}$ Conferência Internacional sobre a Promoção da Saúde realizada em Ottawa, Canadá, no qual o encontro brasileiro originou o Sistema Unificado e Descentralizado de Saúde (SUDS), vigente entre 1986 e 1987 e consolidado na Constituição Federal de 1988, com a afirmação da Saúde como direito de todos e dever do Estado e a criação do Sistema Único de Saúde (SUS), estabelecendo um novo arranjo institucional por separar totalmente esse tema em relação à Previdência, uma vez que essa matéria também estava sob responsabilidade do Ministério da Previdência e Assistência Social desde 1975, por meio da Lei Federal nº 6.229/75, atualmente revogada (CORÁ, 2013).

O advento da Constituição Federal de 1988 estabeleceu o Estado Democrático de Direito com relevante foco na valorização do social, com destacada atenção para saúde que passou a ser considerada prerrogativa universal de todos os brasileiros. A implantação do SUS desde então trouxe a ampliação do amparo a essa garantia fundamental para a coletividade, 
norteadas pelos princípios da universalidade de acesso; integralidade da assistência; equidade; descentralização político-administrativa; participação da comunidade; regionalização e hierarquização (BRASIL, 1988).

Com o advento da Lei $\mathrm{n}^{\circ}$ 8.142, de 28 de dezembro de 1990, há o reconhecimento oficial da participação da comunidade na gestão do SUS, mediante a criação dos Conselhos e das Conferências de Saúde, com o explícito desdobramento do controle social. A população, de forma autônoma, pode intervir no processo para, em conjunto com o órgão gestor, criar estratégias, controlar, fiscalizar e deliberar sobre ações de assistência na área. A regulação feita pela sociedade civil organizada não é tratada como meio do Estado manter a coesão em torno de um projeto hegemônico, uma vez que significa a participação efetiva dos cidadãos sobre as ações estatais, representados em última instância pelas instituições responsáveis pela gerência da saúde, cabendo, portanto, uma atuação ativa do indivíduo na definição das políticas no cenário local, regional e nacional (ASSIS; VILLA, 2003).

Atualmente, os Conselhos e Conferências de Saúde são espaços privilegiados para a explicitação de necessidades e para a prática do exercício da participação e do controle social sobre as políticas de saúde em todas as esferas governamentais. São espaços democráticos de construção de uma nova ordem capaz de revigorar o sentido autêntico de liberdade, democracia e igualdade na sociedade (ASSIS; VILLA, 2003).

\section{CONSELHOS DE SAÚDE}

As conferências e os conselhos de saúde são as principais oportunidades para a prática do controle social na implementação de políticas em todas as esferas de governo, uma vez que atuam como mecanismos democráticos, possibilitando que a sociedade se organize por meio deles para a efetiva proteção da saúde como direito de todos e dever estatal (BRASIL, 2014).

A Lei 8.142/1990, art. $1^{\circ}, \S 2^{\circ}$, estabelece que:

O Conselho de Saúde, em caráter permanente e deliberativo, órgão colegiado composto por representantes do governo, prestadores de serviço, profissionais de saúde e usuários, atua na formulação de estratégias e no controle da execução da política de saúde na instância correspondente, inclusive nos aspectos econômicos e financeiros, cujas decisões serão homologadas pelo chefe do poder legalmente constituído em cada esfera de governo.

Nesse contexto, é possível identificar a competência incumbida aos Conselhos de Saúde de exercer o controle e fiscalização das políticas e gastos públicos na sua área de atuação, cujo papel é de relevante interesse público, uma vez que entre as funções da participação social está a busca de uma apropriada aplicação dos recursos a partir das demandas da população, fazendo com que o papel do controle pela sociedade ganhe maior destaque e relevância. A ativa e contínua operação dessas organizações é capaz de promover um círculo virtuoso de forma a defender os interesses dos cidadãos, propiciar uma rede de sociabilidade humana e ainda o despertar de uma cultura cívica, de forma a contribuir para o fortalecimento da democracia (GONÇALVES et al., 2013).

A composição do Conselho de Saúde é paritária entre aqueles que utilizam o SUS e demais segmentos, ou seja, $50 \%$ dos integrantes dessa organização têm que ser usuários, $25 \%$ devem ser profissionais de saúde e os outros $25 \%$ devem ser gestores e prestadores de serviço na área (BRASIL, 2013).

A depender do tamanho da população local, os Conselhos de Saúde possuem porte variado, mas a regulamentação se mantém para todos, o que proporciona a mesma composição 
paritária. De forma geral, os grupos envolvidos são de características distintas, pois uma vez que não existe no país uma organização própria dos usuários, as entidades representantes da população são de naturezas diversas, como associações de portadores de patologias, sindicatos e assembleias de moradores. Porém, a medicina empresarial privada, da qual o SUS compra serviços, tem discreta presença nas reuniões, apesar de sua importância central. Em vista disso, o tema da representação costuma ser controverso, havendo pesquisas para encontrar mecanismos a fim de alcançar uma paridade igualitária entre os segmentos, bem como a idoneidade dos representantes (LABRA; FIGUEIREDO, 2002).

Conforme a Resolução de número 453 de 2012 do Conselho Nacional de Saúde, este é uma instância coletiva em que representantes do governo (de acordo com cada esfera), profissionais de saúde e usuários estão entre os participantes e o número de conselheiros varia entre 10 e 20 integrantes. O presidente é eleito entre os membros e a representação depende da realidade existente em cada área, preservando-se o princípio da paridade em relação aos usuários, e começam com a presença mínima da metade mais um de seus componentes.

De acordo com o Ministério da Saúde, os Conselhos de Saúde estão presentes em cada esfera de governo como órgãos colegiados, deliberativos e permanentes, pertencentes ao Sistema Único de Saúde (SUS), criados por lei e também considerados de Direito. Possuem aspectos da administração burocrática por apresentarem crença na validade dos regulamentos estabelecidos racionalmente, hierarquia definida, comunicação formal por meio de atas e resoluções, rotinas e procedimentos definidos legalmente, previsibilidade do funcionamento, separação do público e do privado, impessoalidade e processos de trabalho demarcados (BRASIL, 2013).

\section{CONSELHO ESTADUAL DE SAÚDE DE PERNAMBUCO - CES/PE}

Conforme o Regimento Interno do Conselho Estadual de Saúde de Pernambuco (2012), entre as principais competências dessa instituição estão pontos como:

- Participar da formulação, acompanhamento, controle e avaliação da execução da Política Estadual de Saúde;

- Analisar, acompanhar e aprovar o modelo de gestão do Sistema Único de Saúde (SUS) indicado para Pernambuco, assim como a proposta orçamentária equivalente, além de fiscalizar a aplicação de recursos, como aqueles oriundos do Fundo Estadual de Saúde;

- Monitorar e deliberar sobre os processos de descentralização do SUS no estado de Pernambuco e sobre a existência de irregularidades em sua gestão e implantação;

- Apreciar e deliberar sobre a incorporação ou exclusão do SUS, de serviços complementares de saúde, exercendo ampla fiscalização sobre os mesmos;

- Observar e avaliar o processo de desenvolvimento científico e tecnológico na área de saúde, interagindo com técnicos, entidades e organismos em suas reuniões, com vistas a contribuir e a opinar sobre assuntos ligados ao tema;

- Acompanhar e fiscalizar a atuação do setor público e privado suplementar ao SUS;

- Garantir a participação da sociedade na gestão, acompanhamento e avaliação do Sistema Único de Saúde, possibilitando o acesso integral a todas as informações sobre o setor, assegurando que os gestores do SUS promovam a realização de Audiências Públicas para a prestação de contas à sociedade civil sobre orçamento e a política de saúde desenvolvida.

Portanto, as competências regimentais aplicam-se como diretrizes práticas na ação cotidiana do CES/PE, devendo ser conhecidas amplamente pelos membros do Conselho para que não haja desvio de utilidade. Do mesmo modo é importante que sejam difundidas na sociedade a fim de que se esclareça a relevância do controle social exercido por este meio. 


\section{A RACIONALIDADE WEBERIANA}

Em sua obra Economia e Sociedade (2000), Max Weber determina quatro principais categorias de racionalidade: formal, substantiva, meio finalística e quanto aos valores. A do tipo formalizada ou instrumental é composta pela calculabilidade e predicabilidade dos sistemas jurídico e econômico, nos quais há regras, hierarquias, especializações e treinamentos. A modernização se constitui em um processo de consolidação desse gênero racionalista por haver o cálculo utilitário de consequências para as esferas da vida social, antes reguladas pelas interações tradicionais.

Ainda, segundo Weber (2000), a racionalidade substantiva ganha importância a partir das limitações da formal, tomando por base o conteúdo dos fins operacionais dos sistemas legal, econômico e administrativo. Sua divergência da instrumental se dá pela existência de uma lógica estabelecida em função dos objetivos e não dos processos, uma vez que dirige a ação dentro de premissas de valores e, em um sentido mais exclusivamente econômico.

As diferenciações entre racionalidade relacionada a fins e àquela quanto a valores estão diretamente ligadas ao conceito weberiano da ação social, pois este se orienta pelo comportamento de outros, em que o sentido da dinâmica está na própria atividade, só existindo quando o indivíduo tenta estabelecer algum tipo de comunicação com os demais. Um comportamento racionalizado não necessita obedecer a uma lógica última, pois pode existir valor-racional sempre que seus objetivos ou meios sejam de caráter religioso, moral ou éticos, sem conexão direta à lógica formal ou à ciência. Porém, se baseada em valores, sua posição está em um campo extracientífico por serem produtos de escolhas com base em preceitos não diferenciáveis objetivamente (WEBER, 2000).

Segundo Guerreiro Ramos (2006, p. 271), ação social é uma atuação em que "o sentido intencionado por seu sujeito ou sujeitos está referido à conduta de outros, orientando-se por esta em seu desenvolvimento". Seu estabelecimento pode ser dado de modo racional em relação aos fins, aos valores, de modo afetivo ou tradicional.

\section{ESTADO RACIONAL E BUROCRACIA}

Segundo Maliska (2006), o Estado racional é uma comunidade humana que pretende, com êxito, o monopólio do uso legítimo da força física dentro de um determinado território, sendo sinônimo de instituição estatal moderna, que surge apenas no Ocidente, afastando-se do patriarcalismo e patrimonialismo. É sob esta égide baseada no direito lógico e em uma burocracia profissional que irá se estruturar o desenvolvimento do capitalismo moderno.

Para Weber (2000), o Estado é uma correspondência de superioridade de alguns homens sobre outros, apoiada no meio da coação legítima, em que autoridade e legitimidade são os dois elementos essenciais constituintes do sistema.

A legitimidade da dominação pode ser de um dos três tipos puros, em que o primeiro é a autoridade baseada no costume da soberania tradicional típica do patriarcalismo, o segundo é o carismático, em que o comando vem do carisma e do fascínio exercido pelo líder numa relação sustentada pela convicção dos subordinados nas qualidades superiores do mandante, e o terceiro tipo advém da dominação legal, na crença em regimentos e normas, típica do moderno serviço público, pois há soberania racional-legal legítima por meio do direito estatuído de modo racionalizado (WEBER, 2000).

A burocracia foi geralmente entendida como uma forma de poder contendo um dos modos específico de dominação, que se materializa no mundo moderno principalmente por meio das organizações burocráticas. Dois equívocos marcam significativamente a crítica 
negativa ao sistema burocrático: o primeiro é considerá-la um modelo administrativo de natureza apenas técnica e supostamente neutra em termos políticos; o segundo é descontextualizar a história e a metodologia da análise weberiana, interpretando o chamado tipo ideal como modelo prescritivo (CRUBELLATE, 2004).

Para Weber (2001), tipo ideal é um recurso analítico, e não uma prescrição, ou seja, um exagero proposital da realidade a fim de se formar um quadro homogêneo de pensamento. Tal situação se torna impossível de ser encontrada empiricamente na prática, pois devido a sua pureza conceitual, caracteriza-se como uma utopia. Esse conceito é uma tentativa de apreender os seres históricos ou seus variados elementos em definições genéricas.

Um modelo burocrático com um funcionamento totalmente eficiente é um tipo ideal, uma referência ótima de estrutura que deve ser almejada pelo Estado. Dessa forma, quanto mais próximo estiver desta imagem, melhor produtividade funcional haverá. Entretanto, a superestimação dessa positividade pode incorrer em alguns erros. Um ambiente social imaturo pode não absorver os aspectos burocráticos necessários que levem as características positivas ressaltadas por Weber. Por si mesmo, esse sistema não é capaz de superar as deficiências gerais da sociedade em que se encontra, sendo preciso um ambiente propício para que um aparato burocratizado funcione como proposto (GUERREIRO RAMOS, 1983).

Conforme Tragtenberg (2006), a burocracia é um tipo de poder idêntico à organização, possuidor de uma complexidade crescente dentro do sistema capitalista, provocando a adoção na mesma proporção de uma estrutura racional legal caracterizada pela impessoalidade a fim de garantir a reprodução da própria instituição, além de construir sua racionalização com base na divisão do trabalho, que tem, como princípio, os fins.

Em uma pesquisa publicada em 1954, Alvin W. Gouldner realizou uma investigação em uma empresa privada exploradora de gesso e esquematizou genericamente os três sistemas burocráticos identificados. O primeiro seria a burocracia simulada, em que as regras não refletem os interesses de nenhum dos grupos existentes na organização, havendo violação das normas e poucos conflitos entre os envolvidos. O segundo seria o modelo representativo, em que os objetivos de todos os grupos estão presentes nas regras organizacionais aplicadas pela direção e obedecidas pelos trabalhadores, o que gera alguma apreensão, mas raros embates manifestos. Por fim, o tipo autocrático é fundamentado em preceitos que traduzem o interesse de apenas um dos grupos, sejam diretores ou empregados, impostos aos demais membros da organização, gerando tensão e confronto. Apesar do paradigma da representação se mostrar como um avanço em relação às outras, não é lícito afirmar tal fato, pois há risco de se incorrer em um dogmatismo não científico, uma vez que cada uma das estratégias descritas serve como resposta a uma dada circunstância. (GUERREIRO RAMOS, 1983).

Conforme afirma Eisenstadt (1978), uma autonomia estatal politicamente regulada mediante baixa inserção social está na base do equilíbrio dinâmico burocrático, sendo este caracterizado como o sistema detentor de um grau mínimo de autonomia, se tornando capaz de atender às demandas do povo, partindo do princípio que está supervisionado por legítimos titulares de poder. Porém, o autor define dois contextos de quebra do equilíbrio da regulação burocrática: a burocratização, um ganho de autonomia pelo qual o interesse público é restrito a interesses próprios ou particularistas; e a desburocratização, uma situação típica de perda de autonomia que leva à captura da conveniência coletiva por alianças subservientes essencialmente predatórias e parasíticas firmadas entre a burocracia e segmentos externos, da sociedade civil e do organismo político.

A desburocratização ilustra uma situação de inserção disfuncional, uma vez que está implícita no equilíbrio burocrático a ideia de que a regulação política é autossuficiente para assegurar a legitimidade dos sistemas. Logo, esse conceito pode se encaixar como 
desburocratização estatal ou burocratização não estatal, segundo a perspectiva da governança contemporânea (EISENSTADT, 1978).

Robert King Merton (1964) pontua que a burocracia traz em si disfunções, podendo ser analisada em relação ao seu direcionamento para a precisão, a confiança, a eficiência, e de suas limitações para alcançar esses fins, partindo do princípio que a ordem burocrática deve exercer controle para seu funcionamento satisfatório. Entre os desvios burocráticos, estão: internalização e apego às regras, excesso de formalismo, resistência às mudanças, minuciosa conformidade às rotinas e aos procedimentos, dificuldade de atendimento a clientes e conflitos com o público, entre outros.

Fernando Cláudio Prestes Motta (1979) descreve outros autores que defendem transvios no sistema burocrático, como Philip Selznick, que por meio de um estudo em uma agência regional norte-americana pressupôs que esse arranjo se caracteriza pela busca da integração de objetivos de subgrupos à doutrina oficial da organização, estando em conflito permanente na tentativa de legitimação de interesses parciais e não convergentes.

O autor também cita Alvin Gouldner, defensor da ideia de que a origem das perturbações no equilíbrio da organização como sistema maior está na aceitação de diretrizes gerais e impessoais como meio para materializar o controle exigido pela cúpula burocrática. Seguramente, a despersonalização reduz a visibilidade das relações de poder, o que afeta diretamente o papel do supervisor, alterando o nível de tensão interpessoal no grupo de trabalho. Sob outra ótica, um baixo nível de internalização dos objetivos da organização por parte dos funcionários pode provocar níveis mínimos de desempenho admissíveis, aumentando a diferença entre o planejado e o realizado.

\section{PROCEDIMENTOS METODOLÓGICOS}

O método escolhido para elaboração do presente trabalho é composto por revisão da literatura e pesquisa documental. A investigação bibliográfica, ou de fontes secundárias, abrange a bibliografia já publicada em relação ao tema de estudo, a fim de colocar o cientista em contato direto com o máximo de estudos realizados por outros pesquisadores. A análise de documentos é aquela em que a procedência de coleta de dados está restrita aos registros, escritos ou não, constituindo o que se denomina de fonte primária (MARCONI; LAKATOS, 2003).

A base de análise do presente estudo são as publicações oficiais do Conselho Estadual de Saúde de Pernambuco em sua página na internet, especificamente, as resoluções e os resumos das atas das reuniões ordinárias e extraordinárias emitidos em 2017.

A escolha por utilizar o documento resolução como objeto de análise neste estudo vai ao encontro do que determina a Resolução $n^{\circ}$ 453/2012, Quarta Diretriz, no item XII, que trata da estrutura e funcionamento dos Conselhos de Saúde, e que determina a manifestação do Pleno por meio de resoluções, recomendações, moções e outros atos deliberativos, e impõe a esse registro a homologação obrigatória pelo chefe do poder constituído em cada esfera de governo, em um prazo de trinta dias, por meio de publicidade oficial.

Portanto, a execução das competências incumbidas ao CES/PE apenas são realizadas após expressa em manifestação oficial ou atos normativos, por meio de documentos homologados, o que torna essa fonte de informação significativa para que cidadãos não conselheiros e toda população possa acompanhar a eficácia e eficiência da instituição que os representa na regulação societária da saúde. As resoluções representam a decisão institucional de exercer as atribuições de controle social impostas legalmente ao Conselho, sendo o primeiro passo para que haja a efetiva ação fiscalizadora da gestão participativa. 
Em relação às atas, uma vez que são documentos oficiais com o objetivo de registrar as ocorrências, deliberações, decisões e conclusões de uma reunião, é uma relevante fonte de informação a respeito dos assuntos tratados e debatidos durante a plenária do Conselho de Saúde, ainda mais por ser possível comparar aquilo que é discutido e as decisões efetivamente tomadas. As próprias atas geradas após as reuniões não estavam disponíveis no site oficial do CES/PE até o momento da pesquisa. Assim se justifica o uso dos resumos como meio de conhecer os assuntos frequentemente debatidos em plenário, uma vez que foi o material publicado.

Foram analisados doze resumos de atas de reunião e 32 resoluções emitidas, nos quais os primeiros apresentam um padrão em sua construção documental escrita, porém, sem uma formatação rígida. Dessa maneira, o tópico escolhido para análise foi o encerramento, em que consta o título Deliberações/Recomendações, uma vez que está presente de maneira uniforme em todos os documentos. Também é o campo em que estão as decisões e registros finais das reuniões do Conselho, que puderam ser classificadas de acordo com o tema que tratavam.

As resoluções são mais sucintas que os resumos, objetivando regulamentar uma decisão tomada numa dada reunião, a fim de que seja colocada em prática. Assim, as deliberações também foram agrupadas em relação ao tema abordado, sendo possível comparar os temas decididos em debate do plenário, com base nos resumos das atas, e quais foram efetivamente homologados para serem colocados em prática.

A opção de organizar de acordo com o assunto tratado pelo Conselho proporciona uma visão geral sobre o tipo de deliberação que foi tomada pelo CES/PE durante o ano de 2017. Assim, foi possível comparar os temas das decisões com as competências do seu regimento e averiguar o cumprimento do controle social, no sentido de supervisão da sociedade sobre as ações estatais, principalmente, nos quesitos fiscalização, monitoramento ou acompanhamento, avaliação e formulação de políticas públicas de saúde.

\section{ANÁLISE E APRESENTAÇÃO DOS DADOS}

O resultado da análise do item Deliberações/Recomendações dos resumos das atas das reuniões, ordinárias e extraordinárias, do ano de 2017 do CES/PE, originou uma subdivisão em tópicos de acordo com os temas apresentados na Tabela 1.

Verifica-se que a maior parte dos temas constantes no tópico de encerramento Deliberações e Recomendações dos resumos abordam temas intrínsecos ao CES/PE, referentes à administração e organização interna.

Em seguida, estão questões ligadas a eventos, cursos e conferências, voltados tanto para conselheiros como para sociedade, principalmente, referentes a temas como organização e escolha dos participantes. A terceira maior quantidade de temas abordados está na categoria planejamento, gerenciamento e articulação de políticas em saúde, em que estão inclusos debates e apresentação de propostas, projetos, campanhas e de relatórios na área.

$\mathrm{O}$ item orçamento diz respeito a temas voltados à prática de uma das competências fundamentais do CES/PE, orientada para estratégias e controle dos aspectos econômicos e financeiros da execução da política de saúde, como a fiscalização de repasses de recursos e análise de custos para programas na área.

Por último, está o quantitativo de temas voltados para denúncias de irregularidades e fiscalização por meio de inspeção nos locais prestadores de serviços públicos em saúde. Como exemplo prático, podem realizadas visitas nas unidades de saúde a fim de verificar seu funcionamento, diálogo com usuários, funcionários e com a administração do local para conhecer a real situação da oferta de atividades e atendimentos das demandas da população. 
Tabela 1 - Principais temas abordados no item Deliberações e Recomendações dos resumos das atas de reunião do CES/PE em 2017

\begin{tabular}{|c|c|c|c|c|c|}
\hline 2017 & $\begin{array}{c}\text { Administração } \\
\text { interna do } \\
\text { CES/PE }\end{array}$ & $\begin{array}{c}\text { Orçamento } \\
\text { em saúde }\end{array}$ & $\begin{array}{l}\text { Planejamento, } \\
\text { gerenciamento e } \\
\text { articulação de } \\
\text { Políticas em saúde }\end{array}$ & $\begin{array}{c}\text { Denúncias de } \\
\text { irregularidades, } \\
\text { ações de fiscalização } \\
\text { e intervenção in } \\
\text { loco }\end{array}$ & $\begin{array}{c}\text { Eventos, } \\
\text { Cursos e } \\
\text { Conferências }\end{array}$ \\
\hline Fevereiro & 10 & 1 & 2 & 0 & 2 \\
\hline Março & 5 & 0 & 2 & 0 & 4 \\
\hline Abril & 12 & 1 & 5 & 2 & 7 \\
\hline Maio & 5 & 0 & 1 & 0 & 0 \\
\hline Julho & 8 & 2 & 3 & 0 & 1 \\
\hline $\begin{array}{c}\text { Julho } \\
\text { Extraordinária }\end{array}$ & 21 & 0 & 1 & 0 & 4 \\
\hline Agosto & 10 & 1 & 3 & 0 & 23 \\
\hline Setembro & 11 & 0 & 2 & 0 & 8 \\
\hline Outubro & 1 & 0 & 0 & 0 & 0 \\
\hline $\begin{array}{c}\text { Outubro } \\
\text { Extraordinária }\end{array}$ & 1 & 0 & 1 & 0 & 0 \\
\hline Novembro & 9 & 1 & 7 & 2 & 7 \\
\hline $\begin{array}{c}\text { Novembro } \\
\text { Extraordinária }\end{array}$ & 7 & 1 & 6 & 1 & 10 \\
\hline Total & 100 & 7 & 33 & 5 & 66 \\
\hline
\end{tabular}

Fonte: Conselho Estadual de Saúde de Pernambuco - CES/PE

Portanto, a análise dos resumos das atas de reunião no ano de 2017 revela um Conselho, majoritariamente, voltado para suas questões operacionais, em detrimento da dimensão política propriamente dita. Isto posto, percebe-se que foi pouco praticado o controle social focado nas competências de fiscalização, monitoramento e avaliação de políticas públicas de saúde, conforme determinado pelo regimento interno do CES/PE.

A verificação das resoluções emitidas pelo Conselho Estadual de Saúde de Pernambuco no ano de 2017, totalizando uma quantidade de 32, geraram os resultados abaixo, também subdivididos por temas correlatos, conforme Tabela 2.

Verifica-se que o maior quantitativo de resultados gerados em resoluções do CES/PE é referente a assuntos voltados para o funcionamento institucional do próprio Conselho. O maior percentual $(31,3 \%)$ são deliberações sobre a composição de membros tanto da própria instituição como de outros colegiados locais, em convergência com a maior quantidade de debates registrados nos resumos das atas de reunião, passo anterior à decisão final. 
Tabela 2 - Resultados das Resoluções do CES/PE referentes a 2017

\begin{tabular}{|c|c|c|}
\hline Categoria temática & Quantidade & $\begin{array}{l}\text { Percentual } \\
(\%)\end{array}$ \\
\hline $\begin{array}{l}\text { Alteração da composição de membros do Conselho Estadual de Saúde, Comissões } \\
\text { ou Colegiados locais }\end{array}$ & 10 & 31,3 \\
\hline Aprovação de Políticas de Saúde da Secretaria Estadual & 2 & 6,3 \\
\hline Pautas relacionadas a eleições para novos participantes do CES/PE & 2 & 6,3 \\
\hline Normatização de conferências e escolha de integrantes & 4 & 12,5 \\
\hline Aprovação de atas de reuniões & 9 & 28,1 \\
\hline $\begin{array}{l}\text { Aprovação/Revisão do PAS (Programação Anual de Saúde) e RAG (Relatório } \\
\text { Anual de Gestão) }\end{array}$ & 3 & 9,4 \\
\hline Temas relativos a processos de trabalho internos & 2 & 6,3 \\
\hline Total & 32 & 100 \\
\hline
\end{tabular}

Fonte: Conselho Estadual de Saúde de Pernambuco - CES/PE

Em seguida, o maior número de determinações geradas pelas resoluções do CES/PE no ano de 2017 é relativo à aprovação de atas das reuniões, ordinárias e extraordinárias, realizadas regularmente entre os membros do Conselho, com 28,1\% do total dos resultados. Com 12,5\%, está a organização de participantes e normatização de Conferências de Saúde.

Na leitura das resoluções, não foram identificadas deliberações propositivas de políticas de saúde originadas pela plenária de conselheiros. As duas aprovadas em 2017 pelo CES/PE foram elaboradas pelo governo do estado, que seguem: Política de hematologia do estado de Pernambuco e a Política estadual de atenção à saúde integral da mulher. Logo, constata-se que em 2017 a instituição foi, predominantemente, voltada para aprovar propostas oriundas dos gestores e prestadores de serviços governamentais, não contemplando planos de formulação e estratégias de ação, uma de suas competências.

A aprovação/Revisão do PAS (Programação Anual de Saúde) e RAG (Relatório Anual de Gestão) são competências legais e obrigatórias que todos os Conselhos devem cumprir (BRASIL, 2013). Pautas relacionadas a eleições para novos participantes do CES/PE e outros temas diversos relativos a trabalhos internos corroboram com o perfil burocráticoadministrativo predominante em 2017, em detrimento do controle social voltado para fiscalização, monitoramento ou acompanhamento, avaliação e formulação de políticas públicas de saúde.

\section{DISCUSSÃO DOS RESULTADOS}

Em uma observação inicial, o Conselho Estadual de Saúde de Pernambuco se mostra, majoritariamente, voltado para suas questões burocrático-administrativas em detrimento da dimensão política propriamente dita. As decisões tomadas neste espaço são marcadas por temas 
operacionais e não por negociações por parte dos representantes das categorias sociais e o Estado, a fim de garantir a eficiência da prestação dos serviços de saúde à população.

De acordo com as informações oriundas da análise das resoluções e dos resumos das atas, é possível identificar uma nítida predominância dos temas relacionados à organização interna da instituição nas decisões oficializadas, corroborando com o perfil burocráticoadministrativo, predominante em 2017, em detrimento do controle social, ou seja, o CES/PE se revelou pouco eficaz na implementação do accountability societal.

Essas informações podem levar à consideração de que, sendo o Conselho de Saúde uma instituição de características burocráticas, a sua ineficácia em atender, suficientemente, ao seu fim de controle social, registrado em seu regimento, pode ter sido determinada pela chamada disfunção da burocracia, conceito construído pelo sociólogo Robert K. Merton.

Os problemas identificados na análise documental do CES/PE se alinham à concepção acima devido à presença de procedimentos burocráticos descontextualizados que passam a ser objetivos em si, preterindo a finalidade de regulação popular, o que gera ineficácia a partir do momento em que a instituição se preocupa mais com sua operação interna, seguindo, majoritariamente, com o Capítulo III, Seção I, Subseção II - Do Funcionamento, que com a prática de suas competências, presentes do Capítulo II.

Porém, a estrutura burocrática por si só não é responsável pelo desvio finalístico em que os processos de trabalho passam a ser o foco institucional, segundo confirma Guerreiro Ramos (1983), em que a concepção negativa da burocracia é limitada, sendo consequência da superestimação do conceito positivo, que pode ser sobrevalorizado ao ponto de induzir ao engano de que esse sistema sozinho garante a modernidade necessária no ambiente social, uma vez que uma estratégia administrativa ou política tomada como um conjunto exemplar de modos específicos e fixos de agir ou resolver problemas é cientificamente inaceitável.

Ainda, segundo o mesmo autor, a burocracia é episódica, ou seja, suas características atuais não necessariamente serão as mesmas no futuro, uma vez que há mudança do seu caráter conforme a evolução histórico-social acontece. A organização, o sistema burocrático e a racionalidade técnica devem ser apreciados pelo modo como estabelecem suas relações com os que deles se utilizam. Não há modernização racional-legal no sentido de agrupamento social dotado de virtudes intrínsecas, irreversíveis e fixas, pois toda estratégia burocrática renovadora é de ocasião. Porém, na história em curso, a política espontânea dessa tipologia tem sido, essencialmente, predatória e conservadora, jamais inovadora.

Seguindo o raciocínio anteriormente exposto, é possível admitir que o fato do Conselho Estadual de Saúde de Pernambuco ter apresentado uma maioria de deliberações focadas em procedimentos internos em 2017, o que causou um não atendimento eficaz de sua finalidade de controle social, não é consequência direta da forma burocrática de gestão. Sendo esta episódica, faz-se urgente a definição de uma estratégia de ação para a ocasião, a fim de atender aos fins regularmente determinados.

Em outras palavras, o CES/PE carrega uma tradicional estrutura de funcionamento não adaptada para o atendimento dos fins a que se destina, tanto que os resultados de suas resoluções fogem, em sua maioria, do foco das competências pré-estabelecidas em seu regimento. $\mathrm{O}$ alcance dos objetivos finais depende da existência normativa, hierárquica, formal, da relação de poder e de autoridades direcionadas de acordo com as necessidades institucionais, a fim de garantir a eficácia, não se tornando refém de modelos não aplicáveis. O desenho burocrático deve ser alinhado a fim de garantir a maior efetividade organizacional no funcionamento do Conselho, com finalidades, funções e regras explícitas, que devem ser seguidas para o alcance das metas. 
Max Weber (1980) identificou que se a política não fosse forte o suficiente para servir de contraponto aos excessos de profissionalização e autonomia da burocracia, as formas democráticas modernas se inviabilizariam. Para ele, o crescimento burocrático aumenta proporcionalmente o poder dos burocratas. Portanto, o caminho político seria o antídoto para esse problema, o que, por sua vez, depende do fortalecimento do Parlamento, que deve ser ativo, supervisionando e participando continuamente do trabalho da administração.

No caso do objeto desse estudo, os conselheiros adotam igualmente a postura de burocratas no sentido pejorativo da palavra, ao passo que o Conselho deveria agir como um Parlamento, em referência a Weber acima exposto. Ao invés de promoverem um forte ambiente político e participativo, os membros se comportam como aqueles a quem deveriam se contrapor, ou seja, aos ocupantes de cargos governamentais.

A eficiência da burocracia e sua manutenção equilibrada necessitam de ingredientes democráticos atuantes nos mecanismos de regulação e reorientação do seu funcionamento em sistemas sociais diferenciados, em que o controle efetivo sobre a fórmula burocrática possa ser aplicado por meio dos grupos funcionais que participam da estrutura ampla de poder, como os Conselhos de Saúde. Logo, o sistema burocrático deve ser compelido a funcionar como agente que concilia o atendimento das orientações básicas da liderança política com o serviço efetivo às necessidades das camadas sociais majoritárias (OLIVEIRA, 1970).

Destarte, os conselheiros eleitos são os portadores da função política de representação das camadas da sociedade que simbolizam, devendo participar ativamente na administração da máquina burocrática, conforme preveem as legislações que regem o CES/PE. Essa é uma forma de evitar o excesso de autonomia da burocracia do governo de Pernambuco, ao mesmo tempo em que garante a democracia por meio da inclusão de representantes das diversas faixas sociais.

Complementando os pontos abordados anteriormente, o bom desempenho institucional dos Conselhos de Saúde está diretamente ligado ao despertar da consciência socialmente responsável e com a acumulação de capital social, o qual fomenta a instauração de comunidades cívicas capazes de dar sustentação à democracia. Ou seja, é vital o engajamento de cidadãos atuantes e imbuídos de espírito público, que requerem relações políticas igualitárias e uma estrutura comunitária assentada na confiança e na colaboração (LABRA; FIGUEIREDO, 2002).

É de extrema importância a estruturação de programas educacionais para usuários do Sistema Único de Saúde (SUS), com ênfase na participação cidadã, abordando o valor dos Conselhos de Saúde, a fim de contribuir para a expansão do controle social. A mídia e os veículos de comunicação possuem função essencial, devendo ser usados intensivamente para a valorização e incentivo da participação popular por serem notáveis aliados da difusão de informações sobre a relevância do monitoramento e fiscalização de serviços públicos por parte do povo.

\section{CONCLUSÃO}

A análise empreendida nas resoluções e resumos de atas de reunião emitidos durante o ano de 2017 leva ao entendimento de que a prática do Conselho Estadual de Saúde de Pernambuco focou seu funcionamento em questões formais e procedimentos internos em detrimento de suas competências nesse período, tais como a aprovação de políticas de saúde da Secretaria Estadual, normatização de conferências e aprovação/revisão do PAS (Programação Anual de Saúde) e RAG (Relatório Anual de Gestão), entre outras.

A ausência de iniciativas próprias de elaboração de políticas na área de saúde restringiu a ação do CES/PE em 2017, contendo-se como uma alçada formal em que o Estado deve passar 
suas propostas a fim de cumprir a legislação. Tal situação compromete sua competência de planejamento e avaliação na implantação de programas e projetos, uma vez que o Conselho se limita a ser uma instância governamental.

Porém, observa-se que essa conjuntura não é acarretada por um sistema de gestão burocrático por si só, uma vez que este é episódico e sua estrutura deve ser delineada conforme os fins definidos para a instituição. A burocracia não é um todo homogêneo e sua análise não atinge acurácia suficiente quando focaliza apenas aspectos estruturais, uma vez que estes não são associados de maneira uniforme e invariável a determinados comportamentos (GUERREIRO RAMOS, 1983).

O papel dos representantes do governo e da sociedade civil no Conselho de Saúde é garantir que as políticas alcancem as metas determinadas e que os recursos destinados sejam de fato empregados. Essas instituições assumiram um papel central de representação política, tendo em vista os seus dois lados: o processo de autorização e o fomento da accountability societal.

Os conselheiros devem sair do âmbito estrutural interno e instituir mecanismos mais eficientes de contato com a sociedade, a fim de que a população os conheça, de fato e de direito, como agentes fundamentais do controle social, estreitando laços e cumprindo os objetivos da participação popular. Em outras palavras, é preciso que os membros da instituição sejam menos presos à forma de funcionamento e trabalhem por objetivos, no intuito de atingir a eficácia.

Seguindo o pensamento de Max Weber (1980), a burocracia deve ser submetida à moderação política a fim de evitar seu excesso de autonomia e limitar o poder dos burocratas. No caso dos Conselhos de Saúde, a atividade politizada deve ser praticada tanto pelos representantes escolhidos quanto pela população que os escolheu, pois, o envolvimento ativo aumenta a efetividade da gestão participativa.

É preciso maior transparência nas informações a respeito das ações práticas do CES/PE, assim como a divulgação ampla de suas deliberações para que possam ser acompanhadas pela população. A grande mídia e a internet podem ser de grande auxílio nessa definição.

A importância social do Conselho de Saúde de Pernambuco deve ser divulgada para população, a fim de que não seja subutilizado como apenas uma instância formal do governo e para estimular a formação de uma sociedade cívica, em que a cidadania se envolva nos quesitos de interesse coletivo, seja solidária, confiante e tolerante. Esse é um tipo de cultura cuja expressão se materializa em sistemas de participação formados pelas associações do âmbito civil, que compõem um tipo de capital social.

\section{REFERÊNCIAS}

ASSIS, Marluce Maria Araújo; VILLA, Tereza Cristina Scatena. O controle social e a democratização da informação: um processo em construção. Revista Latino-americana de Enfermagem, São Paulo, v. 11, n. 3, p.376-382, jun. 2003. Disponível em: <http://www.periodicos.usp.br/rlae/article/view/1779/1824>. Acesso em: 16 fev. 2018.

BRASIL. Constituição (1988). Constituição da República Federativa do Brasil. Brasília, DF: Senado $\quad$ Federal, $1988 . \quad$ Disponível em: <http://www.planalto.gov.br/ccivil_03/constituicao/constituicaocompilado.htm>. Acesso em: 16 fev. 2018.

Lei $\mathbf{n}^{\mathbf{0}} \mathbf{8 1 4 2}$, de 28 de dezembro de 1990. Dispõe sobre a participação da comunidade na gestão do Sistema Único de Saúde (SUS) e sobre as transferências intergovernamentais de 
recursos financeiros na área da saúde e dá outras providências. Brasília, DF, 1990. Disponível em <http://www.planalto.gov.br/ccivil_03/Leis/L8142.htm>. Acesso em: 09 fev. 2018.

Ministério da Saúde. Conselhos de saúde: a responsabilidade do controle social democrático do SUS. 2. ed. Brasília: Ministério da Saúde, 2013. 28 p. Disponível em: $<$ http://bvsms.saude.gov.br/bvs/publicacoes/conselhos_saude_responsabilidade_controle_2edi cao.pdf>. Acesso em: 09 fev. 2018.

Para entender o controle social na saúde. Brasília: Ministério da Saúde, 2014. 178 p. Disponível em: <http://bvsms.saude.gov.br/bvs/publicacoes/para_entender_controle_social_saude.pdf > . Acesso em: 08

CONSELHO ESTADUAL DE SAÚDE DE PERNAMBUCO. Regimento Interno do Conselho Estadual de Saúde de Pernambuco. Recife: CES/PE, 2012.

Disponível em: <http://www.ces.saude.pe.gov.br/wp-content/uploads/2012/10/RegimentoInterno.pdf >. Acesso em: 09 fev. 2018.

CONSELHO NACIONAL DE SAÚDE. Resolução $\mathbf{n}^{\mathbf{0}}$ 453, de 10 de maio de 2012. Brasília, DF, 2012. Disponível em: <http://conselho.saude.gov.br/resolucoes/reso_12.htm>. Acesso em: 05 set. 2018.

CONTROLADORIA GERAL DA UNIÃO. Controle Social: Orientações aos cidadãos para participação na gestão pública e exercício do controle social. 3. ed. Brasília: CGU, 2012. 43 p. (Coleção Olho Vivo). Disponível em: <http://www.cgu.gov.br/Publicacoes/controlesocial/arquivos/controlesocial2012.pdf>. Acesso em: 14 fev. 2018.

CORREIA, Maria Valéria Costa. Controle Social na Saúde. In: MOTA, Ana Elizabete et al. Serviço Social e Saúde: Formação e Trabalho Profissional. São Paulo: Cortez, 2006. p. 1-29.

COSTA, Ana Maria; VIEIRA, Natália Aurélio. Participação e controle social em saúde. In: FUNDAÇÃO OSWALDO CRUZ. A saúde no Brasil em 2030 - prospecção estratégica do sistema de saúde brasileiro: organização e gestão do sistema de saúde. Rio de Janeiro: Fiocruz/ipea/ministério da Saúde/secretaria de Assuntos Estratégicos da Presidência da República, 2013. Vol. 3. p. 237-271. Disponível em: <http://books.scielo.org/id/98kjw/pdf/noronha-9788581100173-08.pdf>. Acesso em: 29 ago. 2018.

CRUBELLATE, João Marcelo. Participação como controle social: uma crítica das estruturas organizacionais flexíveis. Rae-eletrônica, São Paulo, v. 3, n. 2, p.1-18, dez. 2004. Semestral. Disponível em: <http://www.redalyc.org/pdf/2051/205114648004.pdf〉. Acesso em: 25 fev. 2018.

DURKHEIM, Emile. As Regras do Método Sociológico. 3. ed. São Paulo: Martins Fontes, 2007. 165 p. (Coleção Tópicos). Tradução: Paulo Neves; Revisão de Tradução: Eduardo Brandão. 
EISENSTADT, Shmuel. Burocracia, Burocratização e Desburocratização. In: CAMPOS, Edmundo (Org.). Sociologia da Burocracia. 4. ed. Rio de Janeiro: Zahar, 1978. p. 81-92.

FILGUEIRAS, Fernando. Sociedade civil e accountability societal no controle da corrupção no Brasil. In: GT 04 - Controles democráticos e legitimidade, XXXV ENCONTRO ANUAL DA ANPOCS. Belo Horizonte, MG: agosto, 2011. Disponível em: $<$ https://www.anpocs.com/index.php/papers-35-encontro/gt-29/gt04-19/872-sociedade-civile-controle-social-da-corrupcao-no-brasil/file>. Acesso em: 06 set. 2018.

FONSECA, Francisco César Pinto da et al. Informação, Accountability e Controle Social Análise das Contradições entre Pressupostos da Democracia e Realidade nas Políticas Públicas nas Represas Billings e Guarapiranga. Cadernos Gestão Pública e Cidadania, [S.1.], v. 19, n. 64, p.127-148, abr. 2014. Quadrimestral. Disponível em: <http://bibliotecadigital.fgv.br/ojs/index.php/cgpc/article/view/18907/25695>. Acesso em: 01 set. 2018 .

GUERREIRO RAMOS, Alberto. Administração e Contexto Brasileiro: Esboço de uma Teoria Geral da Administração. 2. ed. Rio de Janeiro: Editora da Fundação Getúlio Vargas, 1983. $350 \mathrm{p}$.

A sociologia de Max Weber: Sua importância para a teoria e a prática da Administração. Revista do Serviço Público, Brasília, v. 57, n. 2, p.267-282, jun. 2006. Trimestral. Disponível em: <http://repositorio.enap.gov.br/bitstream/1/1343/1/2006 Vol.57,n.2 Revisitada - Max Weber.pdf>. Acesso em: 24 fev. 2018.

GONÇALVES, Rodrigo de Souza et al. Conselhos de saúde e controle social: um estudo comparativo dos relatórios de prestação de contas das Secretarias Estaduais de Saúde. Saúde Soc., São Paulo, v. 22, n. 4, p.1001-1013, dez. 2013. Trimestral. Disponível em: $<\mathrm{https}$ ://www.scielosp.org/article/ssm/content/raw/?resource_ssm_path=/media/assets/sausoc/ v22n4/04.pdf >. Acesso em: 03 set. 2018.

LABRA, Maria Eliana; FIGUEIREDO, Jorge St. Aubyn de. Associativismo, participação e cultura cívica: o potencial dos conselhos de saúde. Revista Ciência \& Saúde Coletiva, Rio de Janeiro, v. 7, n. 3, p.537-547, jul. 2002. Disponível em: <http://www.scielo.br/pdf/csc/v7n3/13030>. Acesso em: 16 fev. 2018.

LOPES, José Reinaldo de Lima. Os Conselhos de Participação Popular: validade jurídica de suas decisões. Revista de Direito Sanitário, São Paulo, v. 1, n. 1, p.23-35, nov. 2000. Quadrimestral. Http://www.revistas.usp.br/rdisan/issue/view/1047. Disponível em: <http://www.revistas.usp.br/rdisan/issue/view/1047>. Acesso em: 05 set. 2018.

MALISKA, Marcos Augusto. Max Weber e o Estado Racional Moderno. Revista Eletrônica do Cejur, Curitiba, v. 1, n. 1, p.15-28, dez. 2006. Semestral. Disponível em: $<$ http://revistas.ufpr.br/cejur/article/view/14830/9954>. Acesso em: 25 fev. 2018.

MANNHEIM, Karl. Sociologia sistemática: uma introdução estudo da sociologia. São Paulo: Pioneira, 1962. 238 p. 
MARCONI, Marina de Andrade; LAKATOS, Eva Maria. Fundamentos de Metodologia Científica. 5. ed. São Paulo: Editora Atlas, 2003. 311 p.

MERTON, Robert King. Teoría y Estructura Sociales. México: Fondo de Cultura Económica, 1964. $647 \mathrm{p}$.

MOTTA, Fernando Cláudio Prestes. Controle social nas organizações. Revista de Administração de Empresas, São Paulo, v. 19, n. 3, p.11-25, set. 1979. Bimestral. Disponível em: <http://www.scielo.br/scielo.php?script=sci_arttext\&pid=S0034-75901979000300002>. Acesso em: 29 ago. 2018.

O 'DONNELL, Guillermo. Accountability horizontal e novas poliarquias. Lua Nova: Revista de Cultura e Política, São Paulo, n. 44, p.27-54, 1998. Trimestral. Disponível em: <http://www.scielo.br/pdf/ln/n44/a03n44.pdf>. Acesso em: 31 ago. 2018.

OLIVEIRA, Gersina Alves de. A Burocracia Weberiana e a Administração Federal Brasileira. Revista de Administração Pública, Rio de Janeiro, v. 4, n. 2, p.47-74, dez. 1970. Bimestral. Disponível

em: <http://bibliotecadigital.fgv.br/ojs/index.php/rap/article/viewFile/4847/3585>. Acesso em: 01 set. 2018.

PEREIRA, Ricardo Martins. O controle social na gestão pública: as funções de fiscalização e de ouvidoria dos Tribunais de Contas do Brasil. 2003. 116 f. Dissertação (Mestrado) - Curso de Programa de Pós-graduação em Gestão Pública Para O Desenvolvimento do Nordeste, Universidade Federal de Pernambuco, Recife, 2003. Disponível em: <https://repositorio.ufpe.br/handle/123456789/7868>. Acesso em: 01 set. 2018.

SMULOVITZ, Catalina; PERUZZOTTI, Enrique. Societal Accountability in Latin America. Journal Of Democracy, [S.1.], v. 11, n. 4, p.147-158, out. 2000. Johns Hopkins University Press. http://dx.doi.org/10.1353/jod.2000.0087.

TRAGTENBERG, Maurício. Burocracia e ideologia. 2. ed. São Paulo: Unesp, 2006. 288 p. (Coleção Maurício Tragtenberg).

WEBER, Max. Burocracia. In: GERTH, H.h.; MILLS, C. Wright (Org.). Ensaios de Sociologia. 5. ed. Rio de Janeiro: LTC — Livros Técnicos e Científicos Editora, 1982. Cap. 8. p. 229-277. Tradução: Waltensir Dutra.

Economia e Sociedade. 4. ed. Brasília: Editora Universidade de Brasília, 2000. 464 p. Tradução: Régis Barbosa e Karen Elsabe Barbosa.

Metodologia das Ciências Sociais. 4. ed. São Paulo: Cortez, 2001. 453 p. Tradução: Augustin Wernet.

Parlamentarismo e governo numa Alemanha reconstruída. 2. ed. São Paulo: Abril S.A. Cultural e Industrial, 1980. (Os Pensadores). Tradução: Maurício Tragtenberg. 